\title{
El otoño alemán
}

\author{
German Autumn
}

\author{
SONIA ARribAS \\ ICREA \\ sonia.arribas@upf.edu
}

REsUmen. El terrorismo de la RAF significó el reto más importante al que se tuvo que enfrentar el orden político y económico alemán después de la segunda guerra mundial. El fenómeno es incomprensible si no pone en relación con su enorme presencia y repercusión mediáticas. Éste fue el punto de partida de una exposición que reunió las obras de tres generaciones de artistas que se han ocupado de reflexionar sobre la historia de la RAF.

Palabras clave: RAF, medios de comunicación, arte.

En el 2005 tuvo lugar en Berlín una exposición titulada «Zur Vorstellungs des Terrors: Die RAF» comisariada por Ellen Blumenstein, Felix Ensslin y Klaus Biesenbach. Giró sobre las múltiples representaciones artísticas que se inspiraron desde los años sesenta y setenta en los actos terroristas de la RAF (Rote Armee Fraktion), sobre la recepción y repercusión de tales actos en los media y, de forma igualmente importante, sobre cómo el arte conceptual de los últimos años había estado reflexionando paralelamente sobre el discurso mediático en torno al terrorismo de la banda.

Tres generaciones sucesivas de artistas se habían ocupado de la historia de la RAF: desde Joseph Beuys y Gerhard Richter, pasando por la primera generación de artistas de la posguerra, como
Abstract. RAF's terrorism was the biggest challenge for the German political and economic order after World War II. This phenomenon cannot be properly understood if it is not connected to its great media exposure and impact. This was the starting point of an exhibition that brought together the works of three generations of artists that have reflected about the history of the RAF.

Key words: RAF, media, art.

Martin Kippenberger y Marcel Odenbach, hasta figuras nacidas en torno a finales de los años sesenta, principios de los setenta, como Micaela Meise y Johannes Wohnseifer. Todos ellos reflexionaron sobre la RAF en tanto que fenómeno público en un sentido muy contemporáneo: por su gigantesca repercusión mediática. Sin haber participado en sus actos de manera inmediata o incluso sin haber estado en el círculo amplio de sus simpatizantes, la población alemana entera estaba al tanto de sus protagonistas, actividades y actos terroristas por sus continuas apariciones en los media. Más aún, la experiencia política de la generación coetánea de la banda se alimentó de esa constante presencia en televisión, periódicos y radio. Solo esta exposición mediática puede explicar que tantos artistas del mo- 
mento se dedicasen a representar y analizar el terrorismo de la banda.

La exposición tomó como punto de partida el presupuesto de que el fenómeno RAF es incomprensible sin todo lo que se documentó, escribió y se leyó sobre ella. Y a partir de aquí intentó aprehender el arte que se inspiró en ella, no tanto como una mera reacción frente a sus actos de violencia, o como algo secundario en el universo mediático que la rodeó, sino más bien como parte intrínseca de la realidad mediática que fue la propia RAF.

En esta nota expondré en primer lugar y de manera breve el contexto histórico alemán en el que surgió el terrorismo de la RAF: el paso a la militancia de numerosos jóvenes en los años setenta, el surgimiento de experimentos sociales, la aparición de numerosos grupos a la izquierda de la izquierda parlamentaria (o, más bien, de la gran coalición), el rechazo total al sistema por parte de algunos de ellos, y la radicalización y trágico final de los más conocidos miembros de la banda. La existencia de la RAF significó el reto más importante al que se tuvo que enfrentar el orden político y económico alemán después de la segunda guerra mundial. La segunda parte se centra principalmente en una reflexión sobre el arte que se inspiró o pensó sobre el terrorismo, sobre la perspectiva que tomó la citada exposición en cuanto al fenómeno RAF, y sobre la crítica predominante que recibió tal aproximación entre la izquierda. El punto de partida de la exposición es que ni el terrorismo de la RAF ni el arte de los años setenta y actual que han pensado sobre la violencia terrorista pueden ser desvinculados, para ser comprendidos fehacientemente, de la percepción mediática del terror. El siguiente apartado se dedica a profundizar sobre un tema que apareció en los debates teóricos de muchos movimientos radicales de los años setenta -y aquí sin duda hay que incluir las reflexiones teóricas de los miembros de la RAF_-, a saber, la crisis de la democracia parlamentaria y la violencia asociada al estado, de la mano del célebre texto de Walter Benjamin sobre el tema, «Sobre la crítica de la violencia». Finalmente, en el último apartado me dedicaré a analizar de manera concisa alguna de las obras artísticas que fueron seleccionadas para la exposición. Sin duda alguna, la RAF representa algo que bien podría calificarse como parte de la historia colectiva reprimida de Alemania. Muestra de ello es la todavía predominante incapacidad de hacerse cargo colectivamente de lo que significó.

$$
1
$$

En Alemania la emergencia del arte conceptual vino de la mano de un rechazo frontal a cualquier falta de reflexividad histórica en el arte y como una forma de expresión de resistencias a lo que se sentía como estructuras políticas opresivas, heredadas del reciente pasado nacional socialista. Las nuevas generaciones querían desmarcarse por completo de las actitudes de sus padres y abuelos. Era el tiempo de la influencia de la Internacional Situacionista, del cine experimental y las comunas, de la rebelión y el compromiso político. Un espíritu anti-autoritario sacó a la gente a las calles e insufló de libertad las escuelas, las universidades y las relaciones sociales en general. La juventud alemana protestaba contra la guerra de Vietnam y contra las agresiones imperialistas de occidente.

Todos esos movimientos quedaron a su vez impregnados por la particularidad del terrorismo de la RAF, influyendo de forma indeleble en las generaciones posteriores a la del 68. Las figuras de Andreas Baader, Gudrun Ensslin y Ulrike 
Meinhof se convirtieron en iconos de la protesta y la liberación, pero también de la violencia, la sinrazón y el autoengaño revolucionario. La RAF cohabitó con el movimiento estudiantil emancipador, con novedosos experimentos sociales y con expresiones culturales de enorme influencia en el arte de finales de siglo. Pero fue también sinónimo de la radicalización por medio de acciones violentas que solo condujeron a la miseria y destrucción de sus protagonistas. Se quiso enfrentar a un sistema injusto mediante una violencia paranoica y asesina. Esto tendría consecuencias importantísimas en la cultura y medios de comunicación alemanes, los cuales quedaron profundamente marcados por el fenómeno.

La RAF y sus víctimas, así como el miedo que ocasionó la banda terrorista entre una gran parte de la población, constituyen sin duda alguna uno de los episodios más significativos y terribles de la historia de Alemania Federal. Los actos de la banda afectaron de forma clara al debate político, no solo endureciendo el discurso de la derecha, sino dividiendo muchas veces a la sociedad alemana en campos enfrentados. Fue un símbolo - a veces fascinante- de resistencia, pero también una pantalla donde se proyectaron imágenes de odio, idealizaciones y fantasías encontradas. Estuvo presente de forma constante en las imágenes y caracterizaciones del terror que llenaron los medios de comunicación más importantes los últimos treinta $\mathrm{y}$ cinco años.

La banda fue parte de una generación que creció en la desconfianza frente a la sociedad en la que le tocó vivir, la de la posguerra. Estos jóvenes estaban marcados por la traumática memoria de una violencia radical contra el pueblo judío, aunque ellos mismos no fueran sus responsables. A sus espaldas, padres y abuelos que habían participado de algo con lo que había que romper completamente. En el entorno, una culpa de la que era difícil deshacerse, con la que había que convivir para convertirse en la generación alemana «buena», por venir.

La rebelión del 68 no se entiende sin este doble movimiento de reconciliación imposible entre un responsabilizarse con vergüenza de actos no cometidos pero muy cercanos, por un lado, y el intento de una ruptura definitiva con el pasado. Así confrontaba el hecho de vivir en la devaluación de la experiencia de la generación de la guerra, y limpiaba el presente de la contaminación nacional socialista. Fue una especie de rechazo colectivo motivado por la certeza de la falta de legitimidad del sistema en su conjunto. Su motivación fue la inseguridad y la incomprensión frente a lo propio, el odio, la angustia y la vivencia de un vacío de referencias e ideales positivos.

El combate frente al autoritarismo fue el lema dinamizador de muchas protestas. Había que inventarse una tradición, buscarse unos padres o abuelos alternativos, antiautoritarios y rojos: Mao, Fidel o Marx. Otras referencias teóricas importantes fueron las de las figuras que tuvieron que exiliarse durante la guerra: Marcuse, Adorno, Horkheimer, Reich o Bloch. En Alemania, pero también en otras partes del mundo, la idea directriz de la lucha fue construir una oposición internacional, una resistencia de los jóvenes y los pueblos oprimidos frente a los ricos y poderosos del mundo. Esta tarea imposible desembocó en algunos casos en un tomarse la justicia por su mano, en un hacer su propia ley y sus propios ideales.

La radicalización vino de la mano, en muchas ocasiones, de la creencia en la vinculación directa entre el fascismo y el capitalismo, o la equiparación entre el fascismo y la sociedad burguesa que les 
tocó vivir. En las propuestas más radicales, se observaba que ese proceso ya se había consumado, sea en la versión del estado del bienestar autoritario, o en la condición social de reificación total. Pero tampoco se asomaba el socialismo real como una alternativa viable: su existencia significaba más bien una coartada frente al cambio. Para muchos jóvenes alemanes no se vislumbraba salida alguna hacia un estado liberado que pudiera superar las contradicciones internas de la sociedad capitalista devenida fascista. No se perdía la esperanza en la emergencia de un tercer mundo revolucionario que les salvara frente a la burguesía. Cabía pues apoyar las revueltas de los pueblos del mundo: desde Vietnam a Bolivia, desde el Congo a Oriente Medio.

La historia de la revista konkret, asociada a los movimientos sociales estudiantiles y al movimiento extraparlamentario («Außerparlamentarische Opposition» o APO: formada por aquellos grupos, mayormente estudiantiles, que no estaban de acuerdo con la gran coalición del SPD y el CDU que tuvo lugar entre 1966 y 1969), es ilustrativa de esta radicalización. Fundada por Klaus Rainer Röhl en los años cincuenta, tuvo mucha influencia entre los estudiantes de izquierdas, y contaba con las colaboraciones de periodistas de renombre, entre ellos Ulrike Meinhof, quien llegó a ser su editora jefe ${ }^{1}$. En 1968 se podía leer en sus páginas lo siguiente: «solo desde que comenzamos tímidamente a hablar el idioma del sistema nos hicimos comprensibles por los trabajadores...: éste es el lenguaje de la violencia». Y también: «No vamos a esperar a que todavía otra generación y luego otra generación se arruine, sino que nos defendemos ahora. El socialismo solo lo conseguiremos cuando hacemos saber a nuestros enemigos que vamos a utilizar todos los medios necesarios para lograrlo» ${ }^{2}$. La his- toria del final de konkret es de sobra conocida. Röhl rechazaba el uso de la violencia. El 7 de mayo de 1969 un grupo de radicales irrumpió en su casa, destruyendo las ventanas y el mobiliario. La RAF secuestró a sus hijas (que había tenido con Ulrike Meinhof) un año después. Tras numerosos conflictos en el seno de la revista sobre su orientación política y, en particular, sobre el uso de la violencia, Röhl la abandonó. Al poco tiempo, en 1973, se acabó disolviendo.

Un caso que también conviene recordar en este contexto es el de Rudi Dutschke, el líder estudiantil del movimiento extraparlamentario que se manifestó contra la guerra de Vietnam y luchó por efectuar importantes reformas universitarias contra los dictados de la gran coalición. En 1968 fue víctima de un atentado, perpetrado por un ultraderechista, que le disparó tres tiros en la cabeza. Sobrevivió, pero se pasó un buen tiempo sin poder hablar y las secuelas le duraron hasta su temprana muerte. En medio de esta conmoción llegó a escribir que: «Nuestra alternativa a la violencia reinante es una violencia contraria y creciente ${ }^{3}$. Dutchke estaba pensando en la posibilidad de que el movimiento estudiantil construyera un frente amplio en empresas e instituciones de la sociedad con el objetivo de formar una organización revolucionaria integral. El afán revolucionario le llegó a hacer considerar que el movimiento debería expandirse a nivel internacional para aspirar a destruir tanto el capitalismo como el socialismo autoritario de estado.

El paso a la militancia y la formación de organizaciones políticas que apoyaran la violencia fue algo natural entre algunos. Se fueron estableciendo grupos que combinaban la teoría y la estrategia revolucionarias, con el desarrollo de la educación en comunas (la célebre «Kommune 1») y el agitprop. La pérdida de la 
inocencia se hizo palpable entre 1969 y 1970 , período durante el cual se constituyeron los primeros núcleos de grupos armados.

La RAF fue uno de estos grupos, el más siniestramente romántico, desquiciado y enfrentado al mundo ${ }^{4}$. En sus inicios operó en la clandestinidad. Aunque en su mayoría estaba formada por estudiantes que provenían de la clase media acomodada, tal situación les forzó a mantenerse económicamente por medio del robo a bancos, automóviles y documentos valiosos. (Otros grupos conocidos de aquel momento fueron el movimiento «2. Juni» y las «Revolutionäre Zellen».) El siguiente paso fue el movimiento de guerrillas urbanas por toda Alemania. También buscaron alianzas con terroristas de países en vías de desarrollo $^{5}$. En esta etapa llegaron los asesinatos, los atentados con bomba contra intereses norteamericanos, y los primeros encarcelamientos de sus principales miembros. Los detenidos fueron procesados en 1975 y condenados a cadena perpetua en el ala de alta seguridad de Stuttgart-Stammheim. Se pusieron en huelga de hambre en varias ocasiones para protestar por su situación. El 9 de mayo de 1976 apareció colgado de una cuerda el cadáver de Ulrike Meinhof en su celda de prisión ${ }^{6}$. Durante el proceso de los restantes convictos el fiscal fue asesinado en un ataque terrorista perpetrado por la RAF.

El otoño alemán hace referencia a los trágicos acontecimientos de escalada de violencia acaecidos durante seis semanas en el otoño de 1977, y que habían tenido como presagio el asesinato del director del Dresdner Bank en julio de ese mismo año. El 5 de septiembre fue raptado en Colonia Hanns Martin Schleyer, un antiguo oficial de las SS, en ese momento presidente de la Asociación de Empresarios Alemanes. La RAF se em- pleó a fondo en el uso de los medios de comunicación, divulgando fotos del secuestrado con las siglas y el logo de la banda a sus espaldas. A juicio de uno de los secuestradores, éste era «vínculo ideal entre la postura imperialista del Tercer Reich y lo que vino después» ${ }^{7}$. Los terroristas buscaban presionar al estado alemán para conseguir la liberación de los presos de la RAF (entre ellos Andreas Baader, Jan-Carl Raspe y Gudrun Ensslin) a cambio de la liberación de esta figura prominente del mundo de los negocios. Sin embargo, el entonces canciller Helmut Schmidt decidió junto al líder de la oposición Helmut Kohl, y después de haber mantenido constantes reuniones entre ellos en estado de emergencia, que no habría ningún trato con los terroristas. Aún más, se confinó a los prisioneros en celdas de aislamiento para impedir todo tipo de comunicación entre ellos y con el exterior. Se les prohibieron las visitas. Había que ganar tiempo para que la policía encontrase al secuestrado. Alemania Federal estuvo así prácticamente en estado de excepción: se bloquearon las carreteras y se realizaron búsquedas por todas partes. El conflicto se reprodujo en los medios de comunicación de masas, con presencia continua en las noticias; pero también con una censura informativa, por parte del gobierno alemán, en los canales de mayor difusión. La familia de Schleyer intervino solicitando la satisfacción de las demandas de los secuestradores, pero sin éxito.

La crisis escaló cuando el 13 de octubre fue secuestrado por cuatro árabes el avión del vuelo de Lufthansa que iba de Mallorca a Frankfurt. Algunos miembros de la RAF habían pedido auxilio al Frente Popular para la Liberación de Palestina. El vuelo fue desviado por varias ciudades hasta llegar a Dubai y posteriormente a Aden, en Yemen. La deman- 
da de los secuestradores consistió en la liberación de los presos de la RAF, junto a la de dos palestinos que estaban presos en Turquía, y el pago de un importe cuantioso. La violencia extrema se manifestó cuando el piloto fue asesinado por los terroristas por no aceptar las órdenes de sus captores. Finalmente, el avión fue llevado a la capital de Somalia, Mogadiscio. Los terroristas amenazaron con matar a todos los rehenes.

En una operación altamente secreta, la unidad de élite de la policía federal alemana voló a Mogadiscio y asaltó el avión, acabando con los cuatro raptores y liberando a todos los pasajeros, que salieron completamente ilesos. Esa misma noche Baader y Raspe se suicidaron con unas armas que alguien introdujo en sus celdas. Al parecer, también habían conseguido una pequeña radio. Ensslin apareció colgada de un cable en su celda. El 18 de octubre Schleyer fue asesinado de un disparo en la cabeza.

La exposición trató de poner de relieve la complicada relación que se produjo, a menudo como una disyuntiva, entre el compromiso político y la expresión artística. Los artistas que se sintieron llamados a ofrecer su visión de los acontecimientos del otoño alemán se vieron igualmente compelidos a dar cuenta de su versión de la relación entre el arte y la política, situándose así en la tradición que inauguraron los dadaístas y los surrealistas a principios del siglo xx. Había que diferenciar entre lo que es la definición del arte y lo que es la expresión política. Y reflexionar sobre el posicionamiento del artista con respecto a los problemas y turbulencias sociales del momento. El arte hizo suyos los problemas sociales, y se puso como tarea principal la de poner sobre la mesa los trau- mas de la sociedad alemana. La crítica y el compromiso político tuvieron que ver sobre todo con sacar a la luz estos traumas que en buena medida estaban reprimidos. Los artistas los filtraron y los transformaron en obras de arte, no solo ofreciendo al observador (y a la esfera pública) una posibilidad de reflexión individual, sino también cuestionando los esquemas mediáticos predominantes de interpretación del terrorismo.

En el caso de la representación artística del terrorismo de la RAF era fundamental que no podía evitar mostrar de forma directa la presencia del dolor y del trauma. El arte tenía en este caso una misión comunicativa e iluminadora, de intento de resolución de problemas, pero también una función de provocación e incluso de destrucción. El encuentro con la representación del terror también conllevaba algo traumático en sí mismo. No solo porque estaba en juego la contemplación de un acontecimiento real que había ocasionado tanto dolor, sino también porque, yuxtapuesto a las imágenes más convencionales de periódicos y revistas, el efecto podía ser traumático por partida doble. Por ejemplo, en la exposición estaba el célebre ciclo de fotografías en blanco y negro publicado en forma de libro de Hans-Peter Feldmann llamado Die Toten, en el que figuraban imágenes de periódico de ochenta y siete personas muertas o desaparecidas como resultado de la violencia terrorista europea y la reacción del estado (terroristas, sus víctimas y las víctimas de la violencia estatal) entre 1967 y $1993^{\circ}$. El trauma no residía tan solo en la representación de los actos de violencia y terror, sino también en la presencia continua de la imagen de la muerte y el espanto en fotografías de periódicos. Se trataba de experiencias intensas que desafiaban y producían inseguridad en el espectador y le impelían a cuestionar certezas y buscar interpreta- 
ciones. A juicio de uno de los comisarios, ese aspecto destructor del arte imposibilitaba la producción o erección de un universo simbólico alternativo ${ }^{9}$. Consistía en la reproducción artística de lo ya reproducido ad infinitum por los media, tratando de desmantelar la aparente realidad de lo mostrado, pero sin ofrecer ninguna propuesta positiva.

Los artistas y comisarios de la exposición se propusieron reflexionar sobre el contexto de recepción artístico y mediático de los actos perpetrados por la RAF. $\mathrm{Y}$ muy en particular sobre las transformaciones de los media desde los años sesenta - algo que el impacto social del fenómeno RAF no pudo sino reproducir de forma extrema y muy extendida. Sin los medios de comunicación de masas es incomprensible la gran visibilidad de la $\mathrm{RAF}^{10}$. Ellos influyeron de manera radical en la percepción de la realidad, configurándola. La presencia visual constante de la banda tuvo efectos en la experiencia directa de los acontecimientos históricos. Es asimismo destacable el modo en que la organización se presentó estéticamente ante los medios. El terror fue manipulado por la banda y por los medios de comunicación, a menudo mediante el uso de imágenes impactantes. Hasta el punto de que la experiencia de las imágenes del terror se entremezcló con la experiencia del terror de los espectadores, de tal forma que en muchos casos era difícil distinguir en qué medida se estaba representando el terror ocasionado por la banda o el terror percibido por la esfera pública, impactada de forma repetida por los media. La exposición se preguntó si era posible diferenciar lo que se veía en las imágenes de los media (como acontecimientos que tienen lugar en el mundo) de las representaciones mediáticas como tales. Es decir, intentó poner de relieve la influencia radical de los medios de comunicación en la forma de comprender e interpretar el mundo. Lo que estaba en juego era no solo una interrogación sobre el uso del arte como filtración de experiencias individuales y personales en la narrativa histórica modulada continuamente por los medios de comunicación, sino también una reflexión sobre los efectos sociales de la espectacularización del terror. En este sentido, se preguntó hasta qué punto el arte, en tanto que la empresa por antonomasia de la imaginación, es capaz de representar y documentar el terror en una época de predominancia casi total de los medios de comunicación visuales. ¿Hasta qué punto quedan alterados por la conversión mediática los actos terroristas que se presentan en las obras artísticas?

Como sostiene la comisaria de la exposición, había que tener presente que los protagonistas de los movimientos estudiantiles de finales de los sesenta fueron los primeros en sacar partido de las posibilidades que ofrecen los media para la protesta y la expresión en general ${ }^{11}$. Éste es el motivo por el que los artistas que reflexionaron críticamente sobre el terrorismo de la RAF emplearan también las técnicas y formatos de los media. Desde retransmisiones de vídeos en directo, hasta la fotografía, el documental y el empleo de materiales periodísticos, carteles, etc. La captura mediática del terror se convirtió pues tanto en el contenido material como en el pretexto formal para la expresión artística.

Hay que tener en cuenta además que una de las grandes transformaciones producidas por esta prevalencia total de lo visual en el siglo xx es que muchas imágenes que aparecen en los medios de comunicación figuran ya como si hubieran sido preparadas para la mirada de una cámara omnipresente, que está siempre lista para fotografiar, filmar y hacer público cualquier acontecimiento privado. La reproducción ad infinitum por 
medios técnicos y electrónicos de estas imágenes ha transformado nuestra relación con lo visual de manera dramática. Por su parte, el arte de finales del siglo ha tenido la capacidad, mediante el empleo de diversas técnicas, de distanciarnos y extrañarnos frente a la constante presencia de imágenes impactantes en los medios de comunicación de masas. Ha reflexionado sobre hasta qué punto es posible hacer uso del miedo y el sufrimiento de los otros en la esfera pública masificada.

Es evidente que las obras de arte consiguen mostrar de una forma muy directa la percepción y el sentimiento del terror. Lo interesante tiene lugar, sin embargo, cuando las imágenes del terror son apropiadas y reproducidas por los medios de comunicación de masas, constituyendo ellas mismas un mundo virtual de dolor, pánico, sufrimiento y shock. ¿Pueden llegar a incorporarse a lo que podríamos llamar con mucha precaución la conciencia colectiva de la sociedad, logrando así una especie de educación en la memoria, y apelando a la no repetición de la violencia? O más bien, ¿no aparecen estas imágenes en los medios de comunicación transfiguradas en sus efectos, como una cara más de la publicidad y el juego de las emociones virtuales? Está claro que las imágenes del terror y la catástrofe han sido explotadas hasta la saciedad por la industria del entretenimiento, la llamada al consumo y la búsqueda de emociones visuales. En esta situación, las impresiones se desconectan del contexto inicial de su emergencia y entran en otra dimensión, la comercial, transformando el afecto que expresan para producir efectos muy distintos. La historia misma puede ser convertida en mito.

¿Tenía que aspirar la exposición a la desmitologización de la historia? ¿Y que posicionarse sobre las situaciones socia- les y políticas ocurridas en el otoño alemán? Su objetivo fue más bien el de mostrar el trasfondo generador de la producción de imágenes mediante la yuxtaposición de materiales de archivo, documentos históricos y representaciones artísticas. Su título - «Sobre la representación del terror»_ indicaba que se estaba pidiendo al visitante que se colocara de una forma reflexiva como espectador y observador del terror, dejando en un segundo plano la dimensión política de la RAF.

El ensayista y filósofo alemán Klaus Theweleit criticó esta decisión argumentando que una exposición de este tipo solo tiene sentido si va de la mano de una autorreflexión política por parte de la izquierda. Así, sobre el otoño alemán mantuvo en una entrevista:

Creo que el 1977 fue un sacrificio semiconsciente de la RAF. Sus así llamados partidarios tenían mala conciencia para con la RAF porque no querían luchar con armas. Al mismo tiempo, querían convertirse en una izquierda parlamentaria en orden. La RAF estaba de camino a la muerte - y tras Mogadiscio y los suicidios, la historia finalmente acabó- . Ahora podría hacer cosas la izquierda ecológica y parlamentaria y sin ser molestada. (...) La transformación de la izquierda en 1977 estuvo vinculada con la muerte, con el sacrificio simbólico de la RAF. Eso debería haber mostrado la exposición. De lo contrario se convierte en una historia políticamente neutralizada. Sin auto-reflexión de la izquierda no se puede decir nada de la RAF ${ }^{12}$.

La RAF llevó hasta sus últimas consecuencias la idea de la praxis, conduciéndola hasta su realización extrema bajo la forma de actos cada vez más radicales. La izquierda, quiso decir Theweleit, no puede no tomar partido entre lo que estaba justificado y lo que no. De una forma negativa, la historia de la banda mostró también los callejones sin salida a los que llegó la izquierda a partir de 1968. Habría que haber puesto de re- 
lieve los horizontes que su trayectoria cerraba, así como los horizontes que sí que se abrieron con el surgimiento de una izquierda orientada hacia la defensa de los derechos humanos, la ecología, y diversos procesos participativos, incluido el proceso parlamentario. Daniel CohnBendit por su parte señaló a la banda RAF como representativa del camino más falso y equivocado de la izquierda revolucionaria. En un artículo sobre el tema subrayó repetidamente el error de sus miembros y el de esos muchos de entre la izquierda, predominantemente urbana, que secretamente les apoyaron. Consistió en juntar de una forma ideológicamente confusa, y sin saber medir las consecuencias de sus actos, fantasmas del peor estilo, una idea muy falsa de la solidaridad, cierta paranoia y una fijación con la autoridad. Por otro lado, su noción del Estado como un ente odioso al que había que combatir por todos los medios no llevó nada más que a la indignación y a la rebeldía. Y concluyó:

Pero estoy seguro: si no hubieran existido la RAF y sus caminos extraviados, habría sido la República Federal Alemana hoy un poco mejor $(. . .)^{13}$.

\section{Y en referencia a la izquierda:}

De hecho, se pueden extraer de las mismas circunstancias y de iguales creencias consecuencias bastantes diferentes. Algunos hacen el mundo tal vez mejor; los otros son terribles. Para aprender, para distinguir el bien del mal, también se debe tener en cuenta a la RAF: lo han hecho mal ${ }^{14}$.

La exposición, sin embargo, no aspiró a realizar tan directamente este tipo de reflexiones sobre las transformaciones de la izquierda, la violencia y sus víctimas. Su objetivo más bien fue el de visualizar la inmensa producción de fantasías e imágenes en torno al terror: tanto en la esfera pública mediatizada, como en la izquierda, como también en torno al estado.

En este sentido, la percepción de un visitante nacido antes de los sesenta pudo haber sido muy distinta de la de los principales visitantes de la exposición, gente más joven. Para el primero, aquélla fue su historia; el joven por su parte ha vivido la predominancia de los medios de una forma muy distinta y seguramente desconoce o sabe muy poco de gran parte de los acontecimientos reflejados en los documentos. Los actos terroristas de los años setenta son para él o ella nada más que los nombres e imágenes de sus protagonistas. Estas imágenes aparecen mezcladas en la televisión e Internet con las de otros personajes de lugares lejanos, proyectadas todas simultáneamente en las infinitas pantallas que nos inundan, tanto en la esfera privada como en la pública. En buena medida, la predominancia total de los medios convierte a las transformaciones sociales en episodios de una película que no tiene fin. Para ambos, sin embargo, el encuentro con el arte y la documentación de la representación del terror puede ser traumática, no solo por la violencia de las imágenes, sino también porque los fuerzan a posicionarse sobre las propias identificaciones narcisistas, sobre psicosis individuales y sociales, sobre la escenificación espectacularizada del terror e incluso, como ya señaló Guy Debord, sobre la revuelta convertida en mercancía vía los medios de comunicación de masas ${ }^{15}$.

La superposición de «lo real», lo documental, lo periodístico y lo artístico intentó iluminar los actos terroristas de la RAF como objetos por antonomasia del sistema mediático productor de imágenes, primeras líneas y exclusivas. En la medida en que el espacio elegido fue el artístico, esto es, un lugar público pensado para la creación y la provocación de reflexiones críticas y análisis sobre las 
condiciones de la experiencia del terror y los media - esto es, un lugar no diseñado para la búsqueda de consensos políticos y sociales - el objetivo fue asimismo el de hacer existir de una forma distinta las imágenes del terror. Era imposible poner entre paréntesis y no cuestionar el papel de los medios de comunicación como máquinas generadoras de imágenes de shock. Pues, tal y como escribió Susan Sontag, en el tiempo de predominancia total de los medios de comunicación, un trauma solo puede llegar a ser percibido y hecho consciente cuando, más allá de los impactos, los impulsos y las reacciones constantemente ocasionados por las imágenes del dolor y del terror, puede pasar a ser descrito $\mathrm{y}$, más aún, recordado por una colectividad ${ }^{16}$.

\section{3}

El texto de Walter Benjamin «Hacia una crítica de la violencia», publicado en 1921, ha recibido mucha atención por el mundo académico en los últimos años ${ }^{17}$. Sus tesis centrales, sin embargo, no se pueden entender desconectadas de las experiencias de la primera guerra mundial y los debates posteriores sobre la crisis de la democracia parlamentaria burguesa alemana. Así lo remarca claramente Benjamin cuando escribe que sus reflexiones se hacen «en relación a las condiciones europeas actuales» y se refieren a la «legislación europea actual». También cuando dice que están concernidas con «esa misma violencia que el derecho actual intenta sustraer del comportamiento del individuo en todos los ámbitos, y que todavía provoca una simpatía subyacente de la multitud en contra del derecho». En esas condiciones «realmente amenazadoras» ${ }^{18}$ esos debates emergieron en sus orígenes sobre todo en círculos de la derecha. En las reflexiones de los años sesenta y setenta volvieron a tener lugar, no sin alguna modificación, en los grupos de izquierda, y muy en particular por aquéllos de entre estos grupos que criticaron el monopolio de la violencia estatal y buscaron formas de participación democrática extraparlamentarias. Es por eso que nos interesa ahora.

Benjamin planteó el debate de la violencia estatal en los términos de la filosofía del derecho y la teoría de la justicia. El texto contiene la distinción que tantas páginas ha llenado entre violencia mítica y violencia divina. Lo que le interesa en primer lugar es la violencia mítica: la que se encarga de preservar o crear el derecho y la que busca hacerse con el poder mediante la manifestación inmediata de la violencia.

Benjamin inicia sus reflexiones constatando que la violencia como fin en sí mismo no es defendible, y que lo es tan solo como medio para combatir a un enemigo o resolver un conflicto. También parte de la base de que la violencia no puede ser concebida como estando fuera de la sociedad. Critica el derecho natural argumentando que hay una violencia en el origen de toda ley. La sociedad misma solo funciona por medio de la violencia. Mientras que la violencia del estado es la violencia que está sancionada por el derecho, la violencia individual es la que no lo está. A Benjamin no le interesa discernir si este o aquel uso de la violencia es legítimo. Si su texto se trata de una crítica de la violencia es porque lo que le interesa es averiguar la condición de posibilidad de esa distinción entre violencia sancionada y no sancionada por el derecho. Lo que le preocupa es el derecho a tener derecho a ejercer la violencia. O la pregunta por el funcionamiento de la violencia, su papel, en el contexto de la ley. Más aún, lo que Benjamin llega a decir es que tanto el Estado como el derecho disponen del monopolio de la vio- 
lencia, y que es esto precisamente lo que les legitima. ¿Qué ocurre cuando otras instancias emplean la violencia? Benjamin entra a discutir dos usos de la violencia por instancias no estatales en un sentido estricto: el derecho que los trabajadores tienen de ir a la huelga y el derecho militar. Tanto en un caso como en otro se sobreentiende que se les permite a otras instancias a actuar de derecho, esto es, se sanciona que sus actos son legales. Benjamin localiza aquí una contradicción objetiva: el que el Estado reconozca el ejercicio de la violencia de un acto que, bajo otras circunstancias, podría describirse como violento.

Benjamin también analiza en este contexto el papel de la violencia policial, el cual considera como siendo algo especialmente devastador en una democracia (y a diferencia de una monarquía absoluta, en la que van unidas la supremacía legislativa y ejecutiva). La violencia policial interviene por cuestiones de seguridad cuando el derecho solo del Estado se muestra impotente y no existe ninguna situación legal clara. A diferencia de este derecho, que reconoce que hay una decisión detrás de él determinada por el espacio y el tiempo, en los Estados contemporáneos la institución de la policía tiene un poder amorfo y fantasmal.

Benjamin cree que hay una violencia latente en todas las instituciones. No percatarse de este hecho tiene además consecuencias nefastas. Pone como ejemplo los parlamentos de su tiempo. A su juicio, éstos no caen en la cuenta de que sus orígenes y su existencia misma se deben a fuerzas revolucionarias. Es decir, es imposible pensar el orden legal presente sin el momento histórico de instauración del mismo. Supuestamente cultivan compromisos no violentos en la política, ignorando que ellos mismos representan la violencia creadora del derecho. Aquí Benjamin está en la línea del
Carl Schmitt, crítico de la democracia liberal parlamentaria ${ }^{19}$.

Siguiendo esta línea de reflexión se podría decir que lo que cualquier estado realmente teme es la violencia terrorista, en la medida en que ésta se atiene a una lógica similar a la suya. El Estado tiene el monopolio de la violencia y puede decidir quién es el enemigo, también puede justificar el uso de la violencia. El terrorista ejerce la violencia con miras a crear una situación de derecho que reconozca sus pretensiones. El Estado tiene miedo al acto terrorista en tanto que emplea la violencia como medio para crear nuevas fuentes de derecho. Tiene miedo a cualquier violencia fundadora de derecho que esté en la posición de legitimar o alterar las relaciones de derecho que están dadas. Es decir, a diferencia de lo que podría parecer a primera vista, el terrorista también está vinculado con el origen del derecho en este sentido mítico benjaminiano, no está fuera de él. En sus ambiciones está también la toma del poder (ya sea por parte de «las masas» o del proletariado), y la formación de un nuevo derecho, aunque ni uno ni otro los desvincule nunca de la lucha armada. Esto es algo que se percibe claramente en lo que los miembros de la RAF escribieron sobre la lucha armada y la huelga general. Ambas son contempladas como medios para combatir el estado devenido fascista y la forma parlamentaria de dominación burguesa; con la vista puesta en el resurgimiento político democrático logrado por el proletariado ${ }^{20}$. El terror, escriben en otro texto, es necesario para lograr una política justa y acabar con el sistema de explotación reinante:

[El terror revolucionario] no se dirige, naturalmente que no, contra el pueblo, contra las masas, ni siquiera contra aquellas capas de la población que si bien están cerca del proletariado por su forma de vida y su situación de clase no se pueden decidir de una vez 
a participar en el movimiento revolucionario. El terror revolucionario apunta exclusivamente a los exponentes del sistema de explotación vigentes y a los funcionarios del aparato de represión, a los jefes civiles y militares y cabecillas de la contrarrevolución.... Los señores se sirven del miedo que suscitan con su terrorismo para mantener dóciles a los proletarios. ¿Qué nos obliga a descartar el que los oprimidos, a su vez, se sirvan igualmente del miedo que mediante su terror infunden a sus enemigos para liberarse por fin a sí mismos? ${ }^{21}$

El discurso revolucionario justifica el uso del terror en la medida en que llama al establecimiento de un nuevo orden. El futuro orden se encargará de justificarlo retroactivamente. En Benjamin, se trata de una violencia dirigida a la creación de derecho: un derecho que está necesariamente e íntimamente ligado con la violencia, bajo el título del po$\operatorname{der}^{22}$. Dentro de la violencia mítica, se da una dialéctica entre la violencia fundadora y la violencia que se encarga de preservar el derecho. Esto también es válido desde el punto de vista de los dominados (el proletariado): los dominados demandan la abolición o modificación del orden establecido, y la erección de otro alternativo. El discurso terrorista que supuestamente habla en nombre de los dominados se coloca también en esa violencia mítica que o bien funda o preserva la ley.

\section{4}

La exposición recogió obras de arte realizadas por varias generaciones de artistas. Una particularmente interesante fue la de K. R. H. Sonderborg (1923-2008), un artista que estuvo prisionero dieciocho meses en un campo de concentración de la Gestapo. En el cénit de violencia de los años setenta dibujó ametralladoras. Para la exposición se seleccionó un trabajo de 1983 llamado «Pulver an der
Hand - Blut and der Wand» perteneciente a una serie de dibujos y pinturas realizados entre 1979 y 1984 en el que el artista reflexiona sobre la muerte de Andreas Baader en la prisión de máxima seguridad de Stuttgart. La base consiste en una foto de la celda de prisión sacada de la revista «Der Spiegel» poco después de la muerte de Baader, Meinhof, Ensslin y Raspe, y en la que aparece tal y como había quedado después del fallecimiento. Aísla de esta imagen una manta en la esquina izquierda de la celda, la cual está parcialmente demolida y en la que se ven diversos objetos sanitarios. Se perciben tanto el techo como una barra que había sido empleada para agrietar la pared, fundiéndose las dos formas con la tierra que había caído de la pared en una pintura de color negro sobre un fondo blanco, un cuerpo triangular con dos líneas delgadas y angulares. Los contornos irregulares de las líneas estrechas y recortadas así como la posición de la figura en la imagen dan la impresión de fragilidad e inestabilidad. Unas salpicaduras de pintura en el blanco indican rastros de gotas de sangre, la violencia empleada para producirla, así como los restos del trabajo de los forenses, que se ocuparon de buscar huellas por todo el espacio y los objetos de la celda para encontrar las pruebas de la evidencia del suicidio. En la parte inferior de la imagen en lápiz están las palabras «Polvo en la mano Sangre en la pared». Así se aventura Sonderborg en una interpretación que podría poner en tela de juicio la versión oficial de la muerte de los cautivos. También podría valer como comentario sobre la violencia del Estado en el cuerpo del terrorista y la celda que ocupó. Sin esas palabras es imposible que el espectador capte el tema de la obra de arte.

Otra obra interesante fue la ya mencionada Die Toten de Hans-Peter Feldmann, de 1988. Feldmann hace un tra- 
bajo de recopilación de imágenes de muertos en actos terroristas. Individuos que fueron tanto ejecutores, como víctimas señaladas por los terroristas, rehenes o meros transeúntes con mala suerte. El artista echa mano de imágenes ya publicadas en los medios de comunicación, a la manera de objets trouvés que luego él imprime sobre un papel en blanco y negro. Supone una reflexión sobre cómo estas imágenes tan impactantes ocupan lugares de primera línea en los medios de comunicación, para después ser olvidadas inmediatamente. En ellas solo aparece el nombre del muerto y la fecha de su fallecimiento, sin división alguna entre ejecutores y víctimas (p. e., la foto del empresario secuestrado Hanns Martin Schleyer aparece junto a la del terrorista muerto por inanición Holger Meins), subrayando la anestesia generalizada en la percepción mediática del terror. Sin ningún heroísmo en la violencia, se apunta a la banalidad del mal, en serie. Sin embargo, se perciben algunas diferencias en la textura y calidad de las imágenes, o en la forma en la que las distintas figuras caen bajo el foco central de la cámara o incluso quedan fuera de él. Se trataría de pequeñas marcas de resistencia frente al aura y la mistificación que envuelven las imágenes originales en los medios de comunicación.

Quizá una de las obras de arte más célebres sobre el terrorismo de la RAF fue el ciclo de Gerhard Richter 18. Oktober 1977, expuesto por primera vez en 1989 y vendido al MoMA de Nueva York en $1995^{23}$. Se trata de quince lienzos o, más bien fotopinturas, realizados a partir de imágenes obtenidas de los medios de comunicación del momento y que, en manos de Richter, conmemoran el encarcelamiento y la muerte de los miembros de la Baader Meinhof. El artista rompía así el tabú que hasta el momento reinaba entre la opinión pública alemana de re- cordar este episodio tan doloroso de la historia reciente del país. De forma muy elusiva, en medio de una especie de niebla gris opaca, se vislumbran en algunas de ellas imágenes borrosas monocromo de los terroristas tanto en vida como ya cadáveres. Cada una proviene de una fotografía de periódico cuidadosamente seleccionada por su falta de retórica y su ausencia de juicio moral sobre el asunto. La fecha del título se refiere al día en que los terroristas fueron encontrados muertos en la celda de la prisión de alta seguridad de Stammheim. El ciclo está organizado bajo la forma de un archivo, y cada lienzo recibe un nombre: por ejemplo, «Jugendbildnis» (retrato de juventud), «Beerdigung» (funeral), «Plattenspieler» (tocadiscos - el artefacto donde supuestamente alguién coló una pistola de contrabando para el suicidio), «Erhängte» (colgado) o «Zelle» (celda). Con la tenue luz que ilumina frágilmente cada figura, cada espacio y cada objeto, el artista las dota de un aura misteriosa y artificial. Las imágenes transmiten la fuerza del testimonio de algo terrorífico que no puede ser dicho más allá de estas breves palabras. Intentan construir una representación pictórica del acto de la memoria y de la búsqueda de relaciones entre la experiencia personal y la historia ${ }^{24}$. Aluden a un fracaso colectivo y al dolor producido por este resto no digerido de la historia reciente de Alemania.

\section{BIBLIOGRAFÍA}

Agamben, Giorgio, El poder soberano y la vida desnuda. Homo sacer I, Valencia, Pre-Textos, 1998.

Anónimo, «Gewalt in den Metropolen», konkret, junio 1968.

Arden, Roy, «Hans-Peter Feldmann»: http:/www.ccca.ca/c/writing/a/arden/ arden011t.html/ 
Benjamin, Walter, «Para una crítica de la violencia», en Para una crítica de la violencia y otros ensayos, trad. Roberto Blatt, Madrid, Taurus, 1991, pp. 23-45.

Biesenbach, Klaus (ed.), Zur Vorstellungs des Terrors. Die Raf. Band 2, Göttingen/Berlín, Steidl, Institute for Contemporary Art, 2005.

Boock, Peter Jürgen, «Der deutscher Herbst», Die Zeit: http://www.zeit.de/online/2007/36/bg-deutscher-herbst.

Buchloh, Benjamin H. D., «A Note on Gerhard Richter's “October 18, 1977”, October, vol. 48 (Primavera, 1989), pp. 88-109.

Cohn-Bendit, Daniel, «Deutscher Frühling - Deutscher Herbst», en Zur Vorstellungs des Terrors. Die Raf. Band 2, Göttingen/Berlín, Steidl, Institute for Contemporary Art, 2005, pp. 148-149.

Debord, Guy, La Société du Spectacle, París, Gallimard, 1992.

Derrida, Jacques, Fuerza de ley. El «fundamento místico de la autoridad», trad. Adolfo Barberá y Patricio Peñalver, Madrid, Tecnos, 1997.

Díez Fischer, Agustín, «De Frankfurt a New York: reflexiones sobre la circulación de 18. Oktober 1977», AdVersus, VII, 18 agosto, 2010, pp. 1661978.
Dutschke, Rudi, Briefe an Rudi D., ed. Stefan Reisner, Berlin/Frankfurt, Voltaire, 1968.

Grupo Baader-Meinhof. Fracción del Ejército Rojo, El moderno estado capitalista y la estrategia de la lucha armada, trad. Pedro Madrigal, Barcelona, Icaria, 1977.

Laqueur, Walter, Una historia del terrorismo, trad. Tomás Fernández Aúz y Beatriz Eguibar, Barcelona, Paidós, 2003.

Meinhof, Ulrike, Carta de una presa en la galería de muerte y últimos escritos, Barcelona, Icaria, 1978.

Meinhof, Ulrike et al., Textes des prisonniers de la «fraction armée rouge» et dernières lettres d'Ulrike Meinhof, París, Maspero, 1977.

Meinhof, Ulrike, Pequeña antología, Selección y prólogo de Manuel Sacristán, Barcelona, Anagrama, 1976.

Rodrigo, Miguel, Los medios de comunicación ante el terrorismo, Barcelona, Icaria, 1991.

Schmitt, Carl, Der Begriff des Politischen, Berlin, Duncker \& Humblot, 2002.

Sontag, Susan, Ante el dolor de los demás, Madrid, Alfaguara, 2003.

Theweleit, Klaus, «Kunst muss im Kontext stehen», Tageszeitung, 21 enero 2004.

\section{NOTAS}

\footnotetext{
${ }^{1}$ Manuel Sacristán publicó una selección de textos publicados por Ulrike Meinhof en konkret. En ellos Meinhof escribe sobre temas diversos como varios proyectos de ley de emergencia promulgados en los años sesenta, un congreso celebrado por el SPD en 1964, una campaña de la asociación patronal contra el sindicato metalúrgico en 1966, la visita del vicepresidente de los EE.UU. Humphrey a Berlín en 1967, el uso de la contraviolencia en la universidad (1968) o el proceso por el incendio de unos almacenes en Frankfurt am Main provocado por Gudrun Ensslin y Andreas Baader. Cf. Pequeña antología, Selección y prólogo de Manuel Sacristán, Barcelona, Anagrama, 1976. En
}

las pp. 11-12 del prólogo Sacristán criticó dos, a su juicio, falsedades sobre Ulrike Meinhof y la Rote Armée Fraktion: el de quienes enmarcan la actitud de Meinhof en el sesentayochismo y el de quienes lo hacen en el anarquismo. En p. 15 cita con aprobación a Meinhof en un momento en el que ésta defiende el uso de la violencia revolucionaria frente a la violencia del imperialismo.

2 Anónimo, «Gewalt in den Metropolen», konkret, junio 1968, pp. 25 y ss. Énfasis en el original.

${ }^{3}$ Rudi Dutschke, «Ein Pamphlet». Prefacio a: Briefe an Rudi D., ed. por Stefan Reisner, Berlin/ Frankfurt, Voltaire, 1968, pp. IV y ss. 
${ }^{4}$ La justificación de la violencia como estrategia revolucionaria apareció condensada en varios escritos y podría resumirse en esta idea aparecida en uno de ellos: «La lucha armada como forma más alta de la lucha de clases es algo que resulta del hecho de que las clases poseedoras han logrado asegurarse muy bien su influencia, decisiva, sobre las palancas del poder estatal; consiguiendo un monopolio del Estado sobre los instrumentos del poder que deciden en última instancia: policía y ejército». Y un poco más adelante: «Los nombres de Auschwitz, Sétif, Vietnam, Indonesia, Amman evidencian el que las matanzas en masa no son, en absoluto, cosas de sistemas de dominación pertenecientes al pasado». Cf. Grupo Baader-Meinhof. Fracción del Ejército Rojo, El moderno estado capitalista y la estrategia de la lucha armada, trad. Pedro Madrigal, Barcelona, Icaria, 1977, p. 11. Las referencias empleadas aquí por la banda son: Marx y Engels, Lenin, Rosa Luxemburgo, Mao Tse-tung, André Gorz y Ernest Mandel.

${ }^{5}$ Walter Laqueur, Una historia del terrorismo, trad. Tomás Fernández Aúz y Beatriz Eguibar, Barcelona, Paidós, 2003, pp. 282-3.

${ }^{6}$ En los círculos simpatizantes de la RAF se dijo que no se trató de un suicidio, sino de un asesinato ejecutado por el Estado alemán. Así aparece escrito, por ejemplo, en la declaración que Jan-Carl Raspe realizó en el proceso de Stuttgart-Stammheim, y que aparece como introducción a la publicación de los últimos escritos de Meinhof. Véase Ulrike Meinhof, Carta de una presa en la galería de muerte y últimos escritos, Barcelona, Icaria, 1978, pp. 13-15. Una reflexión interesante sobre la violencia generadora de más violencia la hallamos en el prefacio que Gean Jenet escribió a estos escritos, unidos en la versión francesa al resto de los documentos que quedaron de todos los que estuvieron en prisión. Véase Textes des prisonniers de la «fraction armée rouge» et dernières lettres d'Ulrike Meinhof, París, Maspero, 1977, pp. 1118, p. 14: «es la brutalidad misma de la sociedad alemana la que ha hecho necesaria la violencia de la RAF». Aquí sostiene Genet que la violencia de la RAF provino de la miseria y desesperanza más absoluta. Apunta también a esa ambigüedad suya de ser por un lado continuadora del ímpetu de mayo del 68, al tiempo que, por otro, lo más contrario al espíritu liberador de las revueltas estudiantiles. En la cronología de estos documentos Klaus Croissant, su redactor, siempre pone la palabra «suicidios» entre comillas.

${ }^{7}$ Peter Jürgen Boock, cit. en «Der deutscher Herbst», Die Zeit. http://www.zeit.de/online/2007/36/bgdeutscher-herbst.

${ }^{8}$ Cada página tiene una fotografía con el nombre de la persona y su fecha de fallecimiento debajo. Al final del libro hay un índice en donde se listan los nombres de todos estos individuos, su lugar y causa de muerte. No hay más comentarios. El libro intenta reflejar el conflicto social de aquellos años. A pesar de su intento de imparcialidad, fue objeto de mucha controversia. Sobre la idea del libro sostiene Feldmann: «Hacia el final de los años ochenta, por casualidad miré en un coche de policía que pasaba y vi dos típicos policías jóvenes, con veintitantos años - la misma edad que tenía mi hijo entonces- Me vino a la cabeza - “¿Qué le podría pasar a estos dos jóvenes policías, con un trabajo tan peligroso?”- Y Y también, “¿Qué podría pasarle a mi hijo?”. Y me acordé en ese momento de las fotos de jóvenes policías y estudiantes que fueron asesinados en los años setenta». Citado en Roy Arden, «Hans-Peter Feldmann»: http:/www.ccca.ca/c/writing/a/arden/arden011t.html/

9 Shamim Momin Im Gespräch mit Felix Ensslin, «"Traummaschine" oder was kommt Danach?», en Zur Vorstellung des Terrors. Die Raf. Band 2, ed. por Klaus Biesenbach, Göttingen/Berlín: Steidl, Institute for Contemporary Art, 2005, pp. 42-48, p. 42.

${ }^{10}$ En nuestro país Miguel Rodrigo analizó el terrorismo como acto de comunicación así como la interrelación entre el terrorismo y los mass media en Los medios de comunicación ante el terrorismo, Barcelona, Icaria, 1991.

${ }^{11}$ Ellen Blumenstein, «Zur Vorstellungen des Terrors und Möglichkeiten der Kunst», en Zur Vorstellung des Terrors. Die Raf. Band 2, pp. 16-24, p. 17.

${ }^{12}$ Klaus Theweleit, «Kunst muss im Kontext stehen», Tageszeitung, 21 enero, 2004.

${ }^{13}$ Daniel Cohn-Bendit, «Deutscher Frühling Deutscher Herbst», en Zur Vorstellungs des Terrors, pp. 148-149, p. 149.

${ }^{14}$ Ibid.

15 Guy Debord, La Société du Spectacle, París, Gallimard, 1992, esp. pp. 33-48.

16 Susan Sontag, Ante el dolor de los demás, Madrid, Alfaguara, 2003.

${ }^{17}$ Especialmente tras la publicación de Jacques Derrida, Fuerza de ley. El «fundamento mítico de la autoridad», trad. Adolfo Barberá y Patricio Peñalver, Madrid, Tecnos, 1997, y de Giorgio Agamben, El poder soberano y la vida desnuda. Homo sacer I, Valencia, Pre-Textos, 1998.

${ }_{18}$ Walter Benjamin, «Para una crítica de la violencia», en Para una crítica de la violencia y otros ensayos. Iluminaciones $I V$, trad. Roberto Blatt, Madrid, Taurus, 1991, pp. 23-45, aquí pp. 26-7.

${ }^{19}$ Carl Schmitt, Der Begriff des Politischen, Berlin, Duncker \& Humblot, 2002. Se trata de la parte más criticada en la lectura que de este texto hace Jacques Derrida.

${ }^{20}$ Véase El moderno estado capitalista y la estrategia de la lucha armada, pp. 19-32.

${ }^{21}$ Ibid., pp. 80-1.

${ }^{22}$ En Benjamin: «La función de la violencia en el proceso de fundación de derecho es doble. Por una parte, la fundación de derecho tiene como fin ese derecho que, con la violencia como medio, aspira a implantar. No obstante, el derecho, una vez establecido, no renuncia a la violencia. Lejos de ello, sólo entonces se convierte verdaderamente en fundadora de derecho en el sentido más estricto y directo, porque este derecho no será independiente y libre de toda violencia, 
sino que será, en nombre del poder, un fin íntima y necesariamente ligado a ella. Fundación de derecho equivale a fundación de poder, y es, por ende, un acto de manifestación inmediata de la violencia» (p. 40). La violencia divina en Benjamin sería la que escapa a esta lógica del establecimiento de la ley y asunción del poder. Suspende o desactiva la dialéctica entre violencia fundadora y conservadora de la ley.
${ }^{23}$ Sobre el circuito recorrido por esta obra en el mercado del arte, véase Agustín Díez Fischer, «De Frankfurt a New York: reflexiones sobre la circulación de 18. Oktober 1977», AdVersus, VII, 18 agosto, 2010, pp. 166-178.

${ }^{24}$ Véase sobre este punto Benjamin H. D. Buchloh, "A Note on Gerhard Richter's "October 18, 1977", October, vol. 48 (primavera, 1989), pp. 88-109. 